\title{
ALIMENTAÇÃO SAUDÁVEL E FUNCIONAMENTO DO SISTEMA DIGESTÓRIO ${ }^{1}$
}

\author{
HEALTHY EATING AND THE OPERATION OF THE \\ DIGESTIVE SYSTEM
}

\section{Lívia Andrade FERREIRA*}

RESUMO: O projeto "Alimentação saudável e funcionamento do Sistema Digestório" foi realizado com o $2^{\circ}$ período C, pré-escolar, da Escola Municipal de Educação Infantil Anísio Spínola Teixeira, situada no bairro Morumbi, na cidade de Uberlândia - MG. A presente experiência surgiu a partir da constatação de que, embora a maioria dos alunos faça suas refeições na escola, muitos se limitam a um tipo de alimento, geralmente o arroz, e não sabem, ao certo, da necessidade de alimentarem-se adequadamente. Por meio do diagnóstico de que a família é a principal influência nos hábitos alimentares das crianças e objetivando maior compreensão sobre a necessidade de uma alimentação balanceada, influenciando diretamente nos hábitos alimentares de seus familiares, busquei então abordar, além da alimentação, o funcionamento do sistema digestório. Sendo assim, optei por experiências concretas, o que envolveu o levantamento de hipóteses e a resolução de problemas, a partir de experiências culinárias, da exploração de conceitos matemáticos e dos cinco sentidos. Foram utilizadas a abordagem da pirâmide alimentar, a pintura de natureza morta, a construção de gráfico de preferências alimentares, a elaboração de maquete do

${ }^{1}$ Embora o termo Sistema Digestivo seja mais difundido em nossa sociedade, optei por utilizar o termo Sistema Digestório, atendendo à nomenclatura anatômica oficial da Sociedade Brasileira de Anatomia, conforme esclarecimentos prestados pelo professor da Faculdade de Medicina da Universidade Federal de Goiás, Joffre M. de Rezende (2006).

* Mestranda em educação pela Universidade Federal de Uberlândia (UFU); graduada em Pedagogia e especialista em Docência na Diversidade para a Educação Básica pela Faced/ UFU. Docente da Rede Municipal de Educação de Uberlândia/MG. Universidade Federal de Uberlândia. E-mail: livia.andrade@ufu.br. 
sistema digestório e a simulação do funcionamento desse sistema, por meio de experiências concretas com alimentos.

Palavras-chave: Escola, Alimentação Saudável, Sistema Digestório.

ABSTRACT: The "Healthy Eating and the functioning of Digestive System" project was carried out with the 2nd period C (pre-school) of the Municipal Preschool Anísio Spinola Teixeira, located in the Morumbi neighborhood of the city of Uberlândia - MG. This experience arose from the observation that although most students take their meals at school, many are restricted to a single type of food, usually rice, and are not sure why the need to feed properly. Through the diagnosis that the family is the primary influence on children's eating habits and aiming that students could better understand why the need for a balanced diet, directly influencing the eating habits of their families, so we sought to address in addition to the power the functioning of Digestive System. So, I opted for concrete experiences, which involved among other experiences to raise hypotheses and problem solving, culinary experiences, exploration of mathematical concepts and using the five senses food, the food pyramid approach, painting still life, graphing food preferences, preparation of Digestive System model and simulation of functioning of Digestive System through concrete experiences.

Keywords: school, healthy eating and digestive system.

\section{INTRODUÇÃO}

A alimentação saudável é uma grande preocupação mundial; o índice de obesidade infantil é algo alarmante, que vem se agravando constantemente com a atual rotina de adultos e crianças, visto que a associação de alimentação rápida e inadequada ao sedentarismo tornouse um hábito comum em nosso país, a saúde das novas 
gerações apresenta-se cada vez mais comprometida, o que foi constatado também na rotina dos educandos da Escola Municipal de Educação Infantil Anísio Spínola Teixeira, situada no bairro Morumbi, na cidade de Uberlândia - MG.

Embora realizem suas refeições na escola, muitas crianças restringem-se a um único tipo de alimento, geralmente o arroz, o que ocorre principalmente pela falta de conhecimento, por não compreenderem verdadeiramente a importância de uma alimentação saudável e balanceada. Esse dado é verificado inclusive na fala de seus familiares, quando afirmam que em casa as crianças não querem se alimentar e demonstram satisfação se a criança ingerir qualquer tipo de alimento, ainda que se trate de uma alimentação inadequada.

Além da alimentação imprópria, havia também um alto índice de desperdício dos alimentos durante as refeições e, embora muitas crianças dessem valor ao alimento por realizarem suas refeições exclusivamente na escola, algumas não percebiam sua importância e não demonstravam preocupação ao descartar os alimentos oferecidos. 
Diante dessa realidade, percebi a necessidade de conscientização dos alunos quanto à importância de uma alimentação variada e saudável, para que pudessem mudar seus hábitos alimentares e atuar criticamente frente aos seus familiares. Partindo do princípio de que não há aprendizado real se os conhecimentos forem impostos como verdades absolutas, optei por uma metodologia na qual as crianças pudessem compreender o porquê da necessidade de um alimento em detrimento de outro, e como estes alimentos atuam em seu organismo, o que está diretamente associado ao conhecimento em relação ao funcionamento do sistema digestório.

Frente a estas colocações, o projeto pedagógico "Alimentação saudável e o funcionamento do Sistema Digestório" buscou de forma interdisciplinar instigar os educandos a repensarem o processo natural da alimentação, que geralmente acontece de forma acrítica, dado que a grande maioria das crianças não sabe ao certo sobre a necessidade da alimentação saudável e nem como os alimentos agem dentro do corpo, não atuam 
criticamente sobre essas informações, alimentando-se mal e jogando comida fora.

O que antes era uma preocupação voltada para os países mais desenvolvidos, passa agora a assombrar de forma global e atinge com significância o Brasil. De acordo com Steck (2013), dados publicados pelo Instituto Brasileiro de Geografia e Estatística (IBGE), em agosto de 2010, mostram que uma em cada três crianças na idade entre 5 a 9 anos estaria com o peso acima do recomendado pela Organização Mundial da Saúde.

Frente a esses dados, a reeducação alimentar passa a ser uma das preocupações de nossa instituição escolar, já que a mesma busca um aprendizado dinâmico e associado à realidade dos alunos. É destaque no Projeto Político Pedagógico da Escola Municipal de Educação Infantil Anísio Spínola Teixeira o desenvolvimento da atitude reflexiva, o autoconhecimento e a responsabilidade individual e coletiva em relação à vida como alguns de seus principais objetivos.

A abordagem da alimentação na educação infantil enquanto objeto de estudo faz uma ponte inegável entre os conhecimentos prévios dos alunos e o desenvolvimento de 
aprendizados significativos para eles. Essa temática faz parte da sua rotina e por este motivo pode incentivar movimentos críticos, levando-os a realizar um processo dinâmico de levantamento de questionamentos e de hipóteses, que podem ser constantemente confrontados com as novas descobertas, gerando um aprendizado crítico e autônomo. A esse respeito, os Referenciais Curriculares Nacionais para a Educação Infantil (1998) ressaltam que o estabelecimento de relações entre os novos conteúdos e os conhecimentos prévios das crianças "possibilitará a elas modificarem seus conhecimentos prévios, matizá-los, ampliá-los ou diferenciá-los em função de novas informações, capacitando-as a realizar novas aprendizagens, tornando-as significativas". Para tal, é importante apresentar as principais propriedades dos alimentos e sua atuação no organismo, de modo que as crianças compreendam a importância de cada tipo de alimento e possam comer de forma racional, entendendo as consequências da alimentação. Abordagem que deve ocorrer contemplando os princípios éticos, políticos e estéticos previstos pelas Diretrizes Curriculares Nacionais 
para a Educação Infantil, já que o objetivo é promover a autonomia, a responsabilidade, o respeito ao bem comum, o exercício da criticidade, a criatividade, a ludicidade e diferentes manifestações artísticas e simbólicas que integram tais eixos.

\section{DESENVOLVIMENTO DA EXPERIÊNCIA}

Para o desenvolvimento do projeto "Alimentação saudável e o funcionamento do Sistema Digestório", primeiramente foi necessária uma pesquisa aprofundada em relação aos componentes de uma alimentação saudável e sobre como se procede a digestão. Além disso, fiz o levantamento de experiências rotineiras das crianças em relação à alimentação, que poderiam aparecer como objeto de pesquisa para estimular a criticidade e curiosidade dos alunos a respeito da temática.

Pensando nisso, levantei questionamentos que acreditei fazerem parte da curiosidade infantil e que poderiam instigá-los na busca pelo conhecimento, quais sejam: por que devemos nos alimentar? Para onde vai a alimentação que ingerimos? Por que nossa barriga emite 
ruídos? Por que soltamos gases? Os outros animais também soltam gases? Quais são os alimentos saudáveis e quais são prejudiciais a nossa saúde?

A partir daí foram levantadas as hipóteses das crianças em relação à alimentação e ao funcionamento do sistema digestório por meio de um diálogo no qual obtive respostas como: "A comida vai para barriga e depois para os pés, para ficarem grandes", "A comida vai para barriga e depois para o bueiro e sai pelo braço", "Para a comida sair da gente, a gente tem que vomitar", "A comida desce, vai para barriga e fica lá para sempre", "Quando a gente bebe água, ela vai para o sangue, quando come vai para o estômago e vai para o braço, aí quando dá vontade de fazer cocô ela sai", "As comidas que fazem mal são flor com veneno, sal, margarina, açúcar e doce.", "As comidas que fazem bem são arroz, feijão, carne, macarrão, morango, uva (...), café, guaraná e suco", "A gente solta pum porque come chocolate, batata ou dá dor de barriga".

Mediante o levantamento das hipóteses das crianças, apresentei a história "Amanda no país das vitaminas", do 
autor Leonardo Mendes Cardoso, e houve a exibição dos vídeos "Educação Nutricional para Crianças" e "Sid, O Cientista - Alimentação Saudável", que abordam a importância de cada grupo alimentar e a necessidade de uma alimentação balanceada, o que foi seguido pela realização de debate sobre as informações contidas no livro e nos vídeos e pelo desenho dos alimentos que os alunos julgassem necessários para uma boa alimentação.

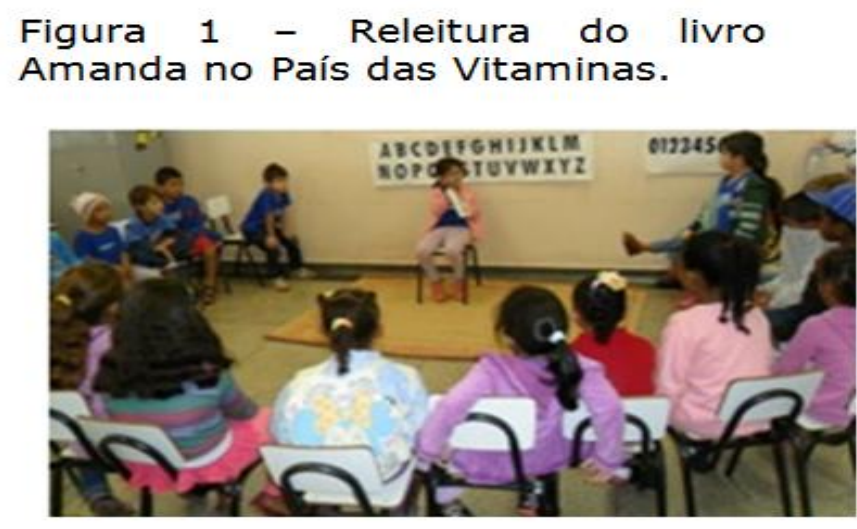

Fonte: A autora.

Os alunos interagiram muito bem com os materiais apresentados e, a partir daí, perceberam a necessidade da alimentação composta por diferentes alimentos, o que fica claro quando afirmam que devemos comer um pouquinho de cada "coisa". 
Para promover a abordagem dos alimentos de forma mais interdisciplinar, aproveitei o contato direto com os alimentos para a realização de uma atividade de identificação, classificação e seriação, na qual as crianças separaram alimentos por tipo (verduras, legumes, frutas, grãos, etc), por cor e por tamanho, em seguida elas contaram e registraram a quantidade de cada grupo alimentar encontrado. Durante a atividade, os educandos demonstraram maior dificuldade na seriação e, por esse motivo, tive que fazer interferências mais frequentes. Entretanto, na identificação e classificação poucos tiveram problemas, os conflitos entre as diferentes opiniões foram facilmente resolvidos pelas próprias crianças, chegando-se a conclusões coletivas.

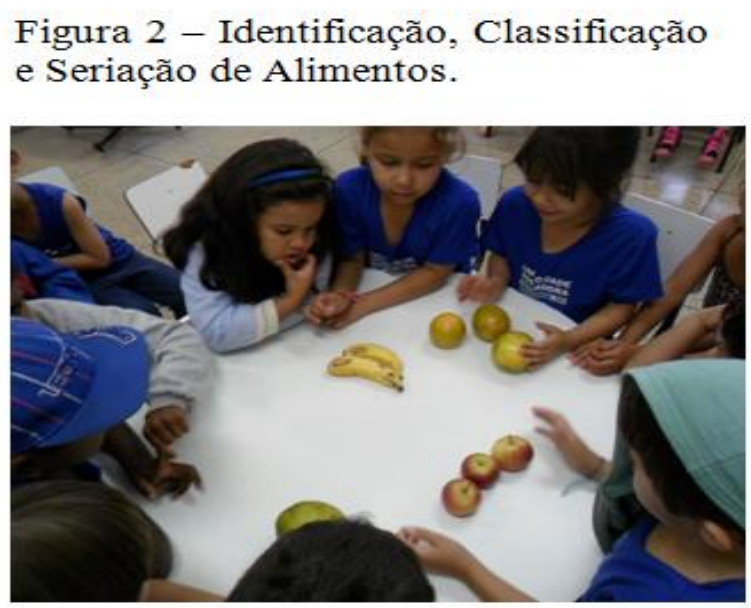

Fonte: A autora. 
Realizamos também uma dinâmica de estímulo aos cinco sentidos, na qual os alunos tentaram reconhecer alguns alimentos utilizando o paladar, o olfato, a visão e o tato. Posteriormente, propus uma brincadeira em que, de olhos vendados, as crianças deveriam encontrar alimentos dispostos na sala através das coordenadas dadas pelos colegas, estimulando o sentido da audição, o movimento e a lateralidade.

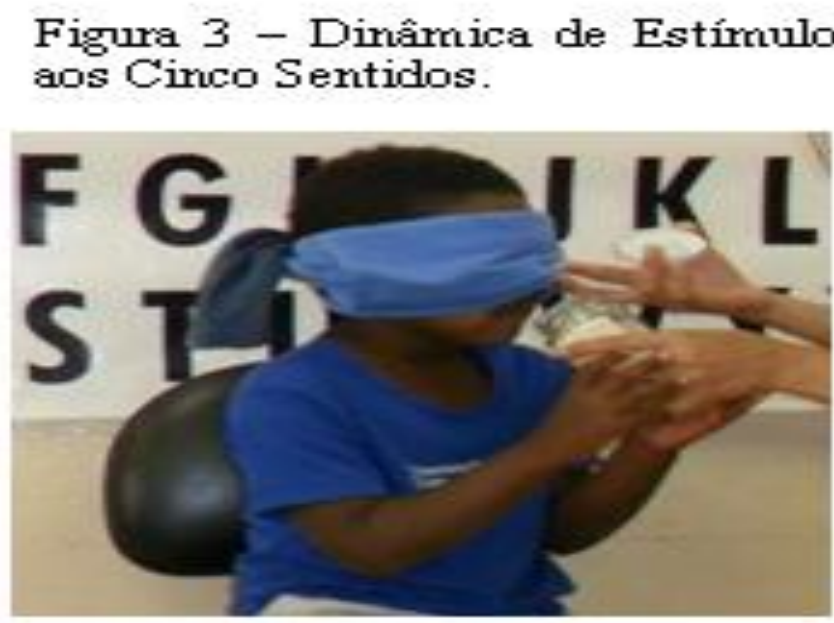

Fonte: elaborada pela autora.

A atividade foi muito proveitosa, em especial após a degustação do mel por um dos alunos, pois todos os demais também solicitaram experimentar o alimento. No entanto, no processo de coordenadas muitas crianças demonstraram dificuldades para direcionar o colega, o que foi interessante para que aguçassem sua lateralidade. 
Outras experiências significativas aconteceram como a confecção de um cartaz de pirâmide alimentar, a pintura de natureza morta observando alimentos dispostos e a construção de gráfico das frutas mais consumidas pelas crianças, explorando conceitos matemáticos importantes para o aprendizado e estimulando noções estéticas.

A confecção dos cartazes com a pirâmide alimentar e com o gráfico das preferências alimentares surpreendeume, pois os alunos assimilaram com facilidade a lógica da pirâmide e construíram o gráfico com uma noção de espaço, o que, mesmo com meu direcionamento, eu não esperava.

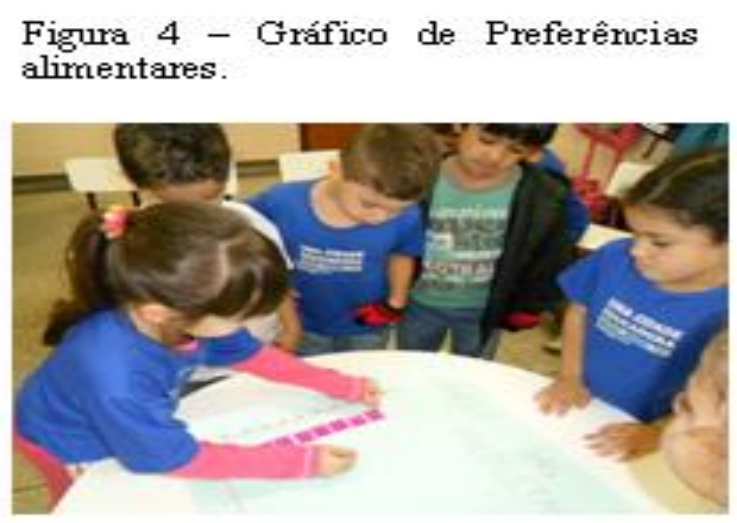

Fonte: elaborada pela autora.

Além disso, conseguiram analisar a pirâmide e os resultados do gráfico de maneira bem simples, havendo nessa atividade uma atuação positiva dos pais, que 
auxiliaram as crianças na coleta de dados em relação a sua fruta predileta.

Uma das propostas mais significativas para as crianças foi a confecção coletiva de uma maquete artesanal do esquema do Sistema Digestório. Nessa experiência, as crianças encheram bexigas com farinha de trigo para simular o estômago, o pâncreas e o fígado, e fizeram os demais canais do Sistema Digestório com massinha, dispondo os materiais sobre um molde de papelão. Mesmo diante da diversidade de opiniões, as crianças conseguiram se entender e cada grupo seguiu sua própria linha de raciocínio, uns fazendo canudos, outros modelando a massa e utilizando-se de pequenos fragmentos dela para representar o esôfago, os intestinos e o reto. 
Objetivando uma melhor compreensão em relação ao processo de digestão, exibi os vídeos "Sid, O Cientista Estômago" e "A digestão de um jeito que você nunca viu", que abordam, de forma lúdica, o funcionamento do Sistema Digestório.

Figura 5 - Maquete do Esquema do Sistema Digestório.

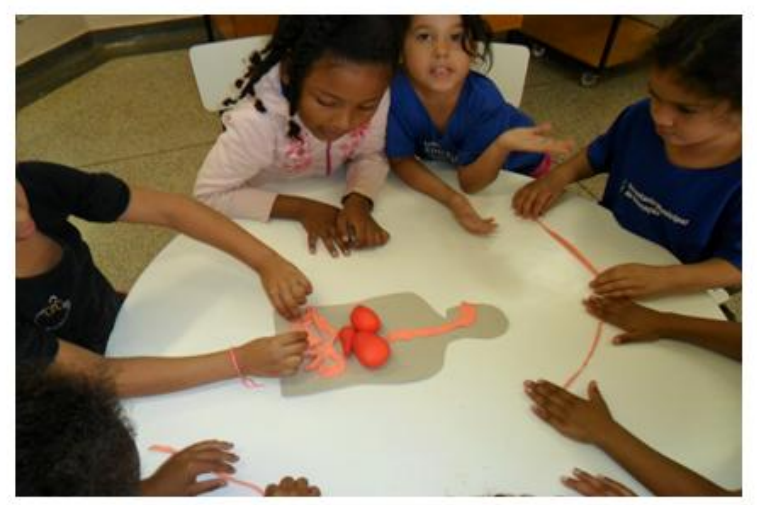

Fonte: elaborada pela autora.

Em seguida houve a reprodução da experiência proposta por esse primeiro vídeo, na qual as crianças simularam a digestão colocando suco de limão dentro de um saco de conservação de alimentos para simular o suco gástrico e inseriram alimentos no recipiente para que se dissolvessem. 


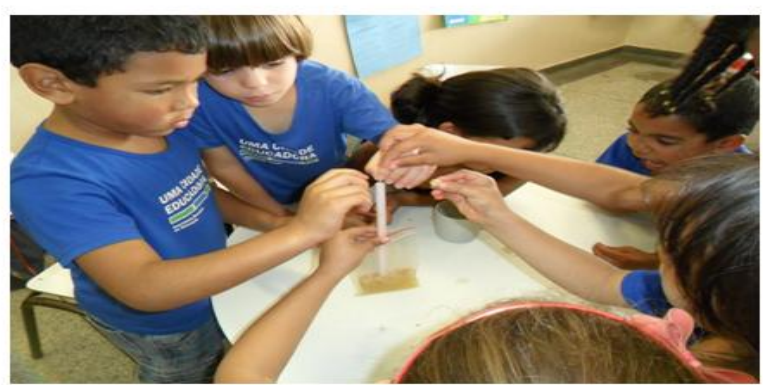

Fonte: elaborada pela autora.

Realizamos também um experimento proposto pela revista Nova Escola. Nele, os alunos tentaram misturar o óleo com a água e, em seguida, inseriram detergente na mistura, simulando a atuação da bile produzida pelo fígado sobre a gordura, que quebra as moléculas de óleo. Realizei interferências durante as exibições dos filmes para chamar a atenção das crianças para alguns pontos, facilitando a compreensão sobre o assunto.

As construções das maquetes e as experiências envolvendo o funcionamento do Sistema Digestório promoveram um aprendizado bem expressivo, pois as crianças compreenderam de forma clara como se processa a digestão dos alimentos e não demonstraram maiores dificuldades para a realização das atividades propostas. E foi a partir daí que surgiram os principais questionamentos, 
alguns dos quais eu não soube responder de imediato, por isso me comprometi a pesquisar junto a eles as respostas. Dentre esses questionamentos estavam: "Por que soluçamos?", "Por que vomitamos?", "Por que fazemos cocô mole?". Diante dessas perguntas, alguns educandos se arriscaram a responder, afirmando que soluçamos porque ficamos descalços ou que temos que beber água para parar de soluçar.

Após a pesquisa em relação aos questionamentos levantados, levei os resultados para discussão durante uma roda de conversa. Alguns temas como o soluço possuem processos complexos, por isso tive que abordá-los de forma a facilitar a compreensão, mas diante das discussões os alunos compreenderam os processos questionados.

Houve também a confecção de vitamina de abacate e de torta de abobrinha realizadas de maneira coletiva por eles. 
Figura 7 - Confecção de Torta de Abobrinha.

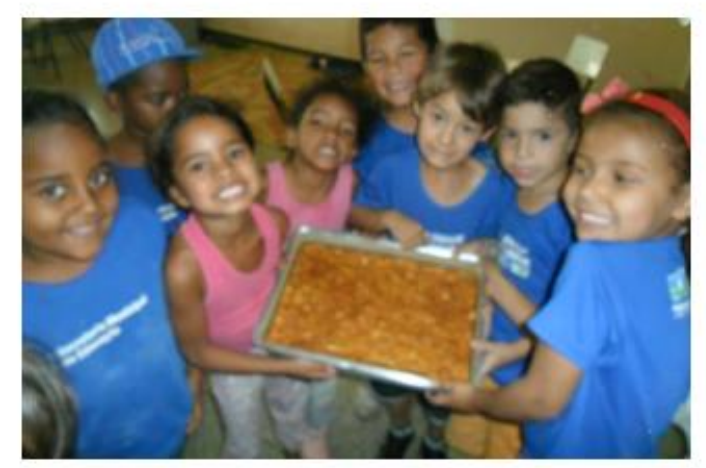

Fonte: elaborada pela autora.

Já que todos participaram da produção do alimento e se comprometeram a experimentar o resultado final, houve uma interação muito boa com a experiência culinária, e todos apreciaram os alimentos com satisfação.

Após a confecção da torta fizemos o registro da receita, utilizando a criatividade individual, de modo a ressaltar a função social da escrita. Os registros foram muito ricos, havendo alguns que representaram os alimentos seguidos do numeral, outros que desenharam os alimentos em suas quantidades junto à imagem de um liquidificador e ainda os que anotaram a receita por meio de escrita silábica. 


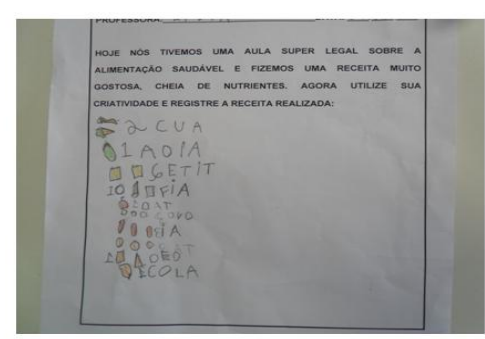

Fonte: elaborada pela autora.

Posteriormente parti para a exibição do vídeo "Saúde com Dr. Esportes", que apresenta de forma lúdica a necessidade de hábitos adequados de higiene, boa alimentação e exercícios para a manutenção de uma vida saudável. Realizamos uma roda de conversa em relação à alimentação e à digestão, registrando as novas conclusões e as hipóteses finais dos alunos por meio de vídeo e anotação.

Diante de todas as vivências ocorridas, enviei para os pais a receita da torta realizada, sugeri que os responsáveis realizassem receitas nutritivas com os alunos e que registrassem a atividade no caderno, por meio de desenhos, fotos ou escritas. Por ser uma atividade mais trabalhosa, obtive um retorno abaixo do esperado, mas os que se dispuseram a participar realizaram tortas, saladas de frutas e sopas, relatos que as crianças fizeram com empolgação. 
A maior parte das crianças demonstrou domínio do conteúdo abordado e interesse pelas atividades propostas, o que foi constatado por meio dos diálogos, dos registros fotográficos (muitas vezes feitos pelas próprias crianças), do envolvimento nas atividades e também das atividades de registro, que apresentaram grande riqueza de detalhes e demonstraram aprendizagens que transcenderam a abordagem do projeto.

\section{CONSIDERAÇÕES FINAIS}

A avaliação do projeto "Alimentação Saudável e o funcionamento do Sistema Digestório" ocorreu de forma processual, por meio da observação das interações, percepções e envolvimento dos alunos com as atividades e da utilização de registros fotográficos, vídeos, desenhos, diálogos e relatórios. Tal avaliação está em consonância tanto com as propostas das Diretrizes Curriculares Nacionais para a Educação Infantil quanto com o Projeto Político Pedagógico (PPP) da Escola Municipal de Educação Infantil Anísio Spínola Teixeira. 
Houve uma exposição de alguns trabalhos realizados durante o projeto, atividade em que os pais e alunos demonstraram satisfação, durante a apreciação dos mesmos. O projeto também participará de uma mostra pedagógica em outubro de 2016, proposta desenvolvida pela escola com o intuito de apresentar alguns resultados dos trabalhos realizados durante o ano e que está prevista no PPP da escola.

Como a alimentação saudável é uma das atividades permanentes, descritas no Projeto Político Pedagógico da Escola Municipal de Educação Infantil, com o intuito de evitar desperdícios e incentivar a alimentação saudável por meio do conhecimento da importância dos alimentos, o trabalho em relação ao projeto será contínuo e a abordagem do tema é permanente.

O desenvolvimento do projeto "Alimentação Saudável e o funcionamento do Sistema Digestório" contribuiu significativamente tanto para meu crescimento pessoal quanto para a aprendizagem significativa dos educandos, ele proporcionou experiências e aprendizagens extremamente valiosas, promovendo o pensar crítico e 
explorando a capacidade de resolução de problemas. Esse aprendizado foi possível devido à utilização de uma temática advinda da própria realidade das crianças, e que por esse motivo favoreceu a participação ativa e o levantamento de hipóteses que contribuirão com a busca de novos conhecimentos.

Além disso, houve um resultado global que influenciou também nas rotinas da instituição escolar, pois, após a experiência, os profissionais que atuam no preparo dos alimentos da escola repetiram o experimento, realizando novas receitas de tortas, com ingredientes presentes na dieta nutricional propostas pela prefeitura.

\section{BIBLIOGRAFIA}

BRASIL, Ministério da Educação e do Desporto. Conselho Nacional de Educação. Diretrizes Curriculares Nacionais para a Educação Infantil. Parecer CEB no 022/98 aprovado em 17 de dezembro de 1998. Relator: Regina Alcântara de Assis. Brasília, DF, 1998.

BRASIL, Ministério da Educação e do Desporto. Secretaria de Educação Fundamental. Referencial curricular nacional para a educação infantil, Brasília, 1998.

CARDOSO, Leonardo Mendes. Amanda no país das vitaminas. São Paulo: Editora do Brasil, 1998. 
CAVALCANTE, Meire. A química que dá gosto de aprender. Revista Nova Escola. Disponível em: $<$ http://revistaescola.abril.com.br/ciencias/praticapedagogica/quimica-gosto-aprender-426142.shtml> . Acesso em: 24 de julho de 2014.

Departamento de Nutrição da Universidade de Brasília. Alimentação saudável disponibilizado. NUT/FS/UnB ATAN/DAB/SPS. Alimentação saudável. Disponível em: $<$ www.telessaude.uerj.br/colorindo-e-

movendo/pdf/colorindo/alimentacao-saudavel.pdf >. Acesso em: 24 de julho de 2014.

IZAC, Danielle Dutra. Alimentação saudável na infância e na adolescência. Jornal do Senado. Jornal Conversa Pessoal. Ano VII, número 97 dezembro de 2008. Disponível em:

$<$ http://www.senado.gov.br/senado/portaldoservidor/jornal Ljornal97/nutricao infancia.aspx>. Acesso em: 24 de julho de 2014.

REZENDE, Joffre $M$ de. Linguagem médica: digestivo e digestório. 03 de março de 2006. Disponível em: $<$ http://www.jmrezende.com.br/digestorio.htm>. Acesso em: 24 de julho de 2014.

STECK, Juliana. Obesidade cresce rapidamente no Brasil e no mundo. Jornal do Senado. 12 de março de 2013. Disponível em: $<$ http://www12.senado.gov.br/jornal/edicoes/2013/03/12/ obesidade-cresce-rapidamente-no-brasil-e-no-mundo $>$. Acesso em: 24 de julho de 2014.

Relato recebido em 10.12.2016 Publicado em 30.12.2016 